\title{
Aspergillus niger causing tracheobronchitis and invasive pulmonary aspergillosis in a lung transplant recipient: case report
}

\author{
Aspergillus niger causando traqueobronquite e aspergilose \\ pulmonar invasiva em transplantado de pulmão: relato de caso
}

\author{
Melissa Orzechowski Xavier ${ }^{1}$, Maria da Penha Uchoa Sales ${ }^{2}$, José de Jesus Peixoto Camargo ${ }^{3}$, \\ Alessandro Comarú Pasqualotto ${ }^{1,3,4}$ and Luiz Carlos Severo ${ }^{1,3,4,5}$
}

\begin{abstract}
A case of invasive aspergillosis caused by Aspergillus niger in a lung transplant recipient is described. The patient presented hyperglycemia starting postoperatively, with other complications such as cytomegalovirus infection. The associated predisposing factors and other implications are discussed. Aspergillus niger seems to be a fungal species of low virulence that requires the presence of a severely immunosuppressed host to cause invasive disease.
\end{abstract}

Key-words: Aspergillosis. Tracheobronchitis. Aspergillus niger. Lung transplantation.

\section{RESUMO}

Descreve-se um caso de aspergilose invasiva causada por Aspergillus niger em um paciente transplantado de pulmão com quadros hiperglicêmicos desde o pós-operatório e outras complicações como infecção por citomegalovírus. Os fatores predisponentes associados e outras implicações são discutidos. Aspergillus niger parece ser uma espécie fúngica de baixa virulência, necessitando a presença de um hospedeiro gravemente imunodeprimido para causar doença invasiva.

Palavras-chaves: Aspergilose. Traqueobronquite. Aspergillus niger. Transplante pulmonar.

Aspergillus tracheobronchitis and invasive pulmonary aspergillosis are frequent clinical presentations of Aspergillus infections in lung transplant recipients ${ }^{11}$. It has been documented that aspergillosis is associated with at least $9 \%$ of the deaths following lung transplant procedures. The vast majority of infections are caused by Aspergillus fumigatus ${ }^{8}{ }^{10}$, followed by other species such as Aspergillus flavus, Aspergillus terreus and Aspergillus niger. Here, we report the unusual occurrence of Aspergillus niger infection following lung transplantation. The implications of these findings are discussed.

\section{CASE REPORT}

A 48-year-old woman had undergone right lung transplantation in 1993 due to idiopathic pulmonary fibrosis. Her early postoperative period was marked by the occurrence of hyperglycemia.
Acute rejection was suspected five days after the surgical procedure because of oxygen desaturation events. Broad-spectrum antibacterial therapy was started, including amikacin, ceftazidime and vancomycin. She was also started on a three-day course of high-dose methylprednisolone $(1,000 \mathrm{mg} /$ day $)$. A transbronchial biopsy revealed the presence of hyaline hyphae infiltrating the lung parenchyma. The hyphae were septate, with acute-angle branching, which was consistent with aspergillosis. Lung biopsy culturing revealed growth of Aspergillus niger. This mould was also recovered from sputum and bronchoalveolar lavage, both cultivated on Sabouraud dextrose agar with chloramphenicol at $25^{\circ} \mathrm{C}$. She was put on a combination of itraconazole $(400 \mathrm{mg}$ daily) and amphotericin B $(1.5 \mathrm{mg} / \mathrm{kg} / \mathrm{day})$, which she took for two months. Further cultures for fungi were all negative.

Over the next months, the patient presented cytomegalovirus pneumonia associated with steroid-resistant rejection. She was

1. Programa de Pós-Graduação em Ciências Pneumológicas, Universidade Federal do Rio Grande do Sul, Porto Alegre, RS. 2. Faculdade Integrada do Ceará, Fortaleza, CE. 3. Santa Casa-Complexo Hospitalar, Porto Alegre, RS. 4. Pesquisadores do CNPq, Brasilia, DF. 5. Faculdade de Medicina, Universidade Federal do Rio Grande do Sul, Porto Alegre, RS.

Address to: Dr. Alessandro C. Pasqualotto. Serviço de Controle de Infecção Hospitalar (SCIH), Hospital Dom Vicente Scherer, Santa Casa de Porto Alegre. Av Independência 75, 90035-075 Porto Alegre, RS, Brasil.

Tel: 5551 9995-1614; Fax: $55513214-8629$.

e-mail: acpasqualotto@hotmail.com

Recebido para publicação em 08/01/2008

Aceito em 08/04/2008 
treated with ganciclovir and the monoclonal antibody OKT3 but developed renal failure, pancytopenia and respiratory failure. She eventually died seven months after the transplant surgical procedure. Autopsy studies revealed foci of bronchopneumonia involving all lobes of the right lung. There was extensive necrosis and suppuration affecting the peribronchial structures, bronchial walls and bronchial mucosa. The right lung parenchyma was diffusely invaded by hyaline hyphae. The left lung showed paraseptal emphysema and extensive bronchiectasis. Septated hyphae showing acute-angle branching were also found invading the left lung parenchyma and the left lower bronchus.

\section{DISCUSSION}

Reports of invasive pulmonary aspergillosis caused by Aspergillus niger are uncommon in the literature ${ }^{26}$. In some of these cases, previous colonization has been suggested as a potential risk factor for invasive disease ${ }^{34}$. The paucity of case reports on invasive pulmonary aspergillosis due to Aspergillus niger has been explained by the limited virulence of this species, since Aspergillus niger is less likely than Aspergillus fumigatus to be associated with invasive disease when recovered from clinical specimens ${ }^{16}$. This has been linked with some physiological, structural and acidophilic characteristics ${ }^{13}$. Firstly, the size of Aspergillus niger conidia $(6-7 \mu \mathrm{m})$ and the presence of strong interspore bridges impair Aspergillus niger penetration into the lower respiratory tract. After inhalation, the spores are therefore easily captured and eliminated by the host mucociliary system $^{13}$. Secondly, Aspergillus niger is less thermotolerant than Aspergillus fumigatus, and its ideal temperature for fungal growth is around $30^{\circ} \mathrm{C}$. This makes germination difficult in the presence of the human body temperature $\left(\sim 37^{\circ} \mathrm{C}\right)^{1}$. The acidophilic nature of Aspergillus niger (ideal $\mathrm{pH} 4.5-4.8$ ) is another limiting condition for fungal pathogenicity ${ }^{13}$.

Although Aspergillus niger has rarely been associated with invasive infections in lung transplant recipients ${ }^{24}$, tracheobronchitis is a common manifestation of aspergillosis in these patients, with incidences ranging from $5 \%$ up to $14 \%{ }^{279}$. In most cases, this occurs after bilateral lung or right single-lung transplantation ${ }^{14}$, as described in the present report. Aspergillus tracheobronchitis should not be seen as a benign condition, since it might progress or coexist with invasive pulmonary aspergillosis ${ }^{5}$, as described in this report.

Similarly to what was demonstrated by other authors ${ }^{15}$, our patient developed invasive endobronchial Aspergillus niger infection following a state of enhanced immunosuppression. She suffered from marked hyperglycemia, starting in the early postoperative period, which was followed by cytomegalovirus infection. Several courses of high-dose corticosteroid therapy were required, in addition to anti-lymphocytic globulin and OKT3 for organ rejection. These are well-known predisposing conditions for invasive aspergillosis ${ }^{911}{ }^{12}$. The short period of antifungal drug treatment (less than two months) that she received was obviously insufficient to completely clear the infection. Accordingly, Aspergillus niger invaded the lung parenchyma and the patient died of invasive pulmonary aspergillosis, which was confirmed by autopsy. This outcome has now been described by several authors ${ }^{7912}$.

In summary, Aspergillus niger is a mould of low virulence that rarely causes infection in transplant patients. As shown in this report, states of marked immunosuppression are usually present in transplant patients with Aspergillus niger infection.

\section{REFERENCES}

1. Abdel-Rahim AM, Arbab HA. Factors affecting spore germination in Aspergillus niger. Mycopathologia 89: 75-79, 1985.

2. Day LJ, Chenoweth CE, Hyde KV, Lynch JP, Iannettoni M, Clark NM. Aspergillus infections after lung transplantation. Infectious Diseases in Clinical Practice 14: 283-288, 2006.

3. Gifford AH, Lahey T, Reyn CFV. Fatal hemoptysis from invasive Aspergillus niger in a patient with cavitary lung disease and Mycobacterium avium complex infection. Medical Mycology 44: 557-560, 2006.

4. Husain S, Paterson DL, Studer S, Pilewski J, Crespo M, Zaldonis D, Shutt K, Pakstis DL, Zeevi A, Johnson B, Kwak EJ, McCurry KR. Voriconazole Prophylaxis in Lung Transplant Recipients. American Journal of Transplantation 6: 3008-3016, 2006.

5. Khoo K, Eng P. Tracheobronchial aspergillosis. Journal of Bronchology 8: 32-33, 2001.

6. Kimmerling EA, Fedrick JA, Tenholder MF. Invasive Aspergillus niger with fatal pulmonary oxalosis in crhonic obstructive pulmonary disease. Chest 101: 870-872, 1992.

7. Mehrad B, Paciocco G, Martinez FJ, Ojo TC, Iannettoni MD, Lynch JP. Spectrum of Aspergillus infection in lung transplant recipients. Chest 119: 169-175, 2001.

8. Mohan A, Guleria R, Mukhopadhyaya S, Das C, Nayak A, Sharma SK. Invasive tracheobronchial aspergillosis in an immunocompetent person. The American Journal of the Medical Sciences 329: 107-109, 2005.

9. Pablo A, Ussetti P, Carreño MC, Lázaro T, Ferreiro MJ, López A, Mendaza P, Estada J. Aspergilosis en el transplante pulmonar. Enfermedades Infecciosas Microbiologia Clinica 18: 209-214, 2000.

10. Patel N, Talwar A, Stanek A, Epstein M. Tracheobronchial pseudomembrane secondary to aspergillosis. Journal Bronchology 13: 147-150, 2006.

11. Paterson DL, Singh N. Invasive aspergillosis in transplant recipients. Medicine 78: 123-138, 1999.

12. Peters JI, Levine SM. Fungal infection in the lung transplant recipient. Clinical Pulmonary Medicine 8: 123-133, 2001.

13. Severo LC, Geyer GR, Porto NS, Wagner MB, Londero AT. Pulmonary Aspergillus niger intracavitary colonization. Report of 23 cases and review of the literature. Revista Iberoamericana de Micologia 14: 104-110, 1997.

14. Singh N, Paterson DL. Aspergillus infectious in transplant recipients. Clinical Microbiology Reviews 18: 44-69, 2005.

15. Singhal P, Usuda K, Mehta AC. Post-lung transplantation Aspergillus niger infection. Journal of Heart and Lung Transplantation 24: 1446-1447, 2004.

16. Wald A, Leisenring W, van Burik JA, Bowden RA. Epidemiology of Aspergillus infections in a large cohort of patients undergoing bone marrow transplantation. Journal of Infectious Diseases 175: 1459-1466, 1997. 